\section{ENIGMATIC EDDINGTON}

\section{The Development and Meaning of Eddington's} 'Fundamental Theory'

Including a Compilation from Eddington's Unpublished Manuscripts. By Dr. Noel B. Slater. Pp. xii +300. (Cambridge: At the University Press, 1957.) 40s. net.

GDDINGTON regarded physics as the structural 1. knowledge of measures of an external world of objects that can be indicated but the intrinsic nature of which is not discoverable. Fundamental physics was for him the part concerned with properties of measures simply as operations, independently of what they operate on. He claimed to have discovered that fundamental physics in this sense comprises all the general laws of Nature, including the evaluation of all the constants involved. His book, "Fundamental Theory" (Cambridge 1946), was the final account of this work. The manuscript was not quite complete when he died in 1944, but was printed as he had left it, under the editorship of the late Sir Edmund Whittaker (who included one of Eddington's published papers on the intended subject of the missing last chapter).

Large parts of five or six earlier drafts had been preserved by Eddington, and Dr. N. B. Slater has collated these in the present book. After summaries of the main sections of "Fundamental Theory", Dr. Slater gives notes on the various drafts and extensive quotations wherever he considers that they contain a significant variant of an argument or material omitted from the final version. He provides a bibliography of writings on the subject that have been of assistance in preparing the book, and a useful list of the symbols employed by Eddington. He has also noted an error in a statistical argument of Eddington's that calls for one or two amendments in the evaluation of certain constants. His task has been extremely onerous, all the more so because the material reached him piecemeal in the course of the work. Clearly, he has exercised the utmost thoroughness, and the plan he has followed is almost certainly the one making for greatest conciseness. Dr. Slater is not to be blamed for the one regrettable feature of the presentation, the smallness of the type used for all quotations from Eddington.

Most physicists would go some way with Eddington in recognizing that their results are not so much properties of an external world as properties of their own operations upon such a world. A number would be glad to be able to go further. Each major conclusion as Eddington describes it in general terms appeals to them as possessing a high degree of plausibility and, if valid, as being profoundly illuminating. Yet they find insuperable difficulty in seeing very much connexion between any such conclusion and the detailed arguments and calculations that purport to establish it. A few physicists are, indeed, prepared to follow Eddington through separate sections of the work but without being satisfied as to the connexions between the sections. So far as I am aware, however, no physicist professes to understand the arguments of "Fundamental Theory" sufficiently thoroughly to be able to assert or deny that it provides a continuous chain of reasoning.

Were Eddington's work acceptable, it would of course be one of the very great advances in scientific thought. The new book might have led to a better understanding of the work had the available material shown how Eddington proceeded from an early stage to build up his final intricate structure. As Dr. Slater remarks, however, almost all the material at his disposal had been intended as a final version when it was written. One cannot, therefore, see much hope that it will help substantially to resolve the enigma of "Fundamental Theory".

The new material, together with Dr. Slater's commentaries, does make clearer than before what Eddington was trying to achieve. Also it shows that Eddington was wonderfully confident that he had achieved it. One cannot help thinking that he has at least indicated the general character of probable developments in physical theory. Such developments may ultimately come from some completely inde. pendent approach, or they may come from work like that of E. W. Bastin and C. W. Kilmister that is probably to some extent inspired by Eddington. But one would hazard the view that they are now scarcely likely to flow directly from Eddington's own treatment. For until acceptable conclusions have been reached by other means, it will probably be impossible to know how far Eddington relied upon his astonishing power of intuition. Nevertheless, Eddington's thought never lost its quality of greatness, even when it was most enigmatic, and we must be grateful to Dr. Slater and the publishers for this additional record of it. $\quad$ W. H. MCCREA

\section{HYDROGRAPHY}

\section{Hydrography of the Faroe-Shetland Channel, 1927-1952}

By Dr. John B. Tait. (Scottish Home Department. Marine Research, 1957, No. 2.) Pp. ix +309. (Edinburgh and London: H.M. Stationery Office, 1957.) 105s. net.

TISHERY scientists have good reason to believe that changes in ocean currents and water circulation have an important bearing on variations in local stocks of fish and migration of fish shoals. For the whole of north-west Europe it is important to have a good knowledge of the varying balance between Arctic and Atlantic influences, and for the North Sea itself we must understand the varying influence of oceanic water which mixes with coastal water and flows from north to south across the herring fishing grounds. The first essential is to have measurements of what has taken place, and the most promising method known so far is to make regular surveys of the changing temperature and salinity of the water. The Faroe-Shetland Channel is a particularly informative area because a large proportion of the Atlantic water that warms the northern North Sea and the Arctic Ocean passes through it.

Dr. Tait's large monograph gives a detailed presentation of the vertical distribution of temperature and salinity along two roughly parallel cross-sections from the Faroe Islands to the Shetland Islands and from the Faroe Bank to the Butt of Lewis. On twenty-two occasions between 1927 and 1952 observations were made along both lines, and on a further twenty-five they were made along one or the other. Every now and then other lines were worked. The monograph gives diagrams showing the distribution of temperature and salinity in the vertical plane for every line of observations, and the observa. tions themselves are listed in Appendix 2. It also 